\title{
IMPORTÂNCIA DAS CUIDADORAS NA CONSTITUIÇÃO PSÍQUICA DE CRIANÇAS INSTITUCIONALIZADAS
}

Importance of Caregivers in Institutionalized Children's Psychological Constitution

Importancia de las Cuidadoras en la Constitución Psíquica de Niños Abrigados

\section{Marjorie C. Rocha da Silva ${ }^{1}$, Geraldo A. Fiamenghi-Jr*2, Jéssica T. Martins ${ }^{3}$, Nellie T.} Martins $^{3}$, Maria de F. Xavier ${ }^{4}$

${ }^{1}$ Curso de Psicologia, USF, Itatiba, Brasil / Curso de Psicologia, UNISAL, Americana, Brasil.

${ }^{2}$ Curso de Psicologia, UNIFAAT, Atibaia, Brasil.

${ }^{3}$ Clínica Particular, Limeira, Brasil

${ }^{4}$ Faculdades Integradas Einstein de Limeira, FIEL, Brasil

*Correspondência: Curso de Psicologia, UNIFAAT, Estrada Municipal Juca Sanches, 1050, CEP 12954-070, Atibaia/SP, Brasil.e-mail geraldoafj@gmail.com

\section{Artigo recebido em 24/04/2018 aprovado em 07/10/2019 publicado em 23/03/2020.}

\section{RESUMO}

O vínculo é uma das formas de se demonstrar a afetividade e permite um desenvolvimento psíquico mais saudável. Esta pesquisa teve o objetivo compreender a importância do cuidado e acolhimento realizado por parte das cuidadoras na construção do vínculo, visando reduzir o sofrimento de crianças institucionalizadas. Foi realizada uma entrevista semiestruturada com nove cuidadoras de uma Associação localizada numa cidade do interior do estado de São Paulo. Os resultados mostraram que as cuidadoras desenvolvem vínculo afetivo com as crianças, e contribuem na amenização dos impactos da institucionalização, uma vez que realizam o papel de figura materna. Em contrapartida, as cuidadoras demonstraram um descontentamento com a instituição referente ao número reduzido de funcionárias, destacando a alta rotatividade como um fator que prejudica o cuidado das crianças. Além disso, apresentaram dificuldades em compreender o limite de envolvimento afetivo com as crianças, para que seja uma relação saudável para ambas as partes. Espera-se que os resultados desta pesquisa forneçam conhecimento às cuidadoras, referente à importância no processo de cuidar, e o papel do vínculo no desenvolvimento psíquico ao longo do processo de abrigamento.

Palavras-chave: afeto; cuidadores; vínculo.

\section{ABSTRACT}

Attachment is a means of showing affection and allows for a healthier psychological development. This research aimed to understand the importance of caring and welcoming by caregivers in attachment building, targeting the reduction of institutionalized children's suffering. A semi structured interview was conducted with nine caregivers of an Association located in a country town in São Paulo. Results showed that caregivers develop attachment to the children and help in lowering the impacts of institutionalization, as they perform maternal roles. On the other hand, caregivers were displeased with the institution due to the reduced number of employees, especially the rota system, as a factor that interferes with children's care. Besides, they showed difficulties in understanding the limits of attachment with the children, for the relationship to be healthy for both parts. It is hoped that this research's results provide knowledge to caregivers, concerning the importance of caring and the role of attachment in psychological development during institutionalization.

Keywords: affect; caregivers; attachment. 


\section{RESUMEN}

La vinculación es una manera de demonstrar afectividad y permite un desarrollo psíquico saludable. Esta pesquisa tuvo el objetivo de comprender la importancia del cuidado y acogida de las cuidadoras en la construcción de la vinculación, para reducir el sufrimiento de niños abrigados. Fue efectuada una entrevista semiestructurada con nueve cuidadoras de una Asociación localizada en una ciudad del interior de São Paulo. Resultados muestrearan que las cuidadoras desarrollan vinculaciones afectivas con los niños y contribuyen en la diminución de los impactos de la institucionalización, porque realizan el papel de figura maternal. En contrapartida, las cuidadoras retrataran una insatisfacción con la institución, relacionada a el número reducido de empleados, especialmente la rotatividad como un factor prejudicial a los cuidados con los niños. También presentaran dificultad em comprender el límite de envolvimiento afectivo con los niños, para que sea una relación saludable para ambos. Se espera que los resultados de esta pesquisa traigan conocimiento a las cuidadoras, referente a la importancia del proceso de cuidar y el papel de la vinculación en el desarrollo psíquico en el proceso de abrigamento.

Descriptores: afecto; cuidadoras; vinculación.

\section{INTRODUÇÃO}

O primeiro ano de vida do bebê é repleto de situações de aprendizagem, um período de plasticidade; de fato, este estágio de desenvolvimento é considerado o período de maior aprendizado da vida do bebê, tanto do ponto de vista do desenvolvimento motor, como emocional e, fundamental para a saúde mental da criança (BOWLBY, 1976; SPITZ, 1965; WINNICOTT, 1965).

Pensando nesse processo de desenvolvimento, vital para a estruturação do ego do bebê, especialmente representado pela mãe nas trocas afetivas e o fornecimento de cuidado, se houver o rompimento do laço afetivo materno, quando não existir um cuidador que a represente, a consequência será a intensificação de sentimentos de insegurança.

De acordo com Spitz (1965), em um desenvolvimento adequado após o bebê obter a diferenciação, avançará a outro estágio, realizando a exploração e experimentação, ampliando seu território, dirigindo-se a uma ação mais estruturada, estabelecendo relação de trocas afetivas com o objeto libidinal (mãe), experimentando suas capacidades e limites adquiridos. Pensando no abrigamento, e as limitações correspondentes às relações com o objeto libidinal, representado pela mãe, entende-se que tais crianças podem apresentar dificuldade em obterem uma estruturação de ego mais elaborada e suficiente para se diferenciarem e constituírem-se como indivíduos inteiros, únicos, e em sua totalidade. O rompimento da relação de trocas afetivas proporcionadas pela mãe pode causar sentimentos de desamparo, uma vez que se estruturam e se constituem nestas relações.

É importante que, no período de institucionalização, a criança possa ter relações de objeto que lhe proporcionem identificações internas e externas significativas, já que o ego como instância fundamental na formação e estabelecimento do aparelho psíquico, deve sua estruturação à relação com a mãe e, posteriormente com familiares e amigos. Nesse sentido, Winnicott (1965) afirma que o ego da criança é fraco e forte concomitantemente, e depende das habilidades da mãe em oferecer suporte em sua estruturação. Bowlby (1976) menciona que crianças abandonadas, ou não receberam afeto, podem apresentar sentimentos de raiva, tristeza e subsequentemente, angústia.

Ao pensar no processo de institucionalização, entende-se o quanto as crianças podem sofrer, pela falta do referencial materno na estruturação do ego e o quanto tal ruptura provoca sentimentos de 
abandono. Portanto, é importante um ambiente favorável para o desenvolvimento adequado

O estudo de Cavalcante, Magalhães e Pontes (2007) demonstrou a precoce e prolongada institucionalização das crianças, a maior parte por negligência da família, na falha ou omissão das funções mais elementares, como a alimentação, o zelo e a proteção de riscos e ameaças graves. No estudo de Santos e cols (2010), as crianças abrigadas apresentavam mais indicadores emocionais que revelavam a ansiedade, timidez, temor e tristeza. Já Souza e Brito (2015) concluem ser necessário oferecer modalidades de proteção à infância e à juventude que valorizem a família e evitem a aplicação da medida de acolhimento institucional.

Num estudo com cuidadoras de um abrigo, foram realizadas intervenções psicoterápicas no intuito de amenizar o sofrimento psíquico causado por identificação das cuidadoras com as crianças abrigadas, refletindo em uma melhora significativa na realidade subjetiva das cuidadoras, bem como na ampliação do contato afetivo com a realidade externa (Careta, 2011). O trabalho de Tagliari (2011) identificou, através dos relatos das cuidadoras que elas se sentem responsáveis pelo bem-estar e das necessidades básicas dessas crianças.

De acordo com Marques, Cano e Vendruscolo (2007), o acompanhamento no processo do cuidado são características fundamentais no desenvolvimento da criança, que norteiam os aspectos biológico, psicológico e social. Segundo Bowlby (1976), é importante proporcionar uma vivência contínua com a mãe biológica ou mãe substituta, que consiga desempenhar o papel materno, e que ofereça cuidados e atenção íntima, que favoreçam para o desenvolvimento mental saudável. Winnicott (1965) afirma que uma das funções maternas se dá pelo holding, no fornecimento de segurança, proteção, sensibilidade, carinho, dentre todos os cuidados diurno e noturno que as crianças necessitam. Ressalta também a importância do toque diante do cuidado, como forma de contato com sua realidade externa. Neste sentido, entende-se o processo vincular estabelecido nestas ações de cuidado, e o quanto essas promovem sentimentos de conforto interno e externo, fazendo que as crianças se sintam acolhidas em seu desenvolvimento físico e psicológico.

Oliveira e Próchno (2010), em um estudo sobre a vinculação de crianças abrigadas, à espera de adoção, observaram nessa situação específica, que as crianças vivenciavam uma relação positiva com as cuidadoras, permitindo uma transição tranquila.

Barros e Fiamenghi-Jr (2007) sugerem que a formação e capacitação das cuidadoras é de fundamental importância para o estabelecimento de relações positivas com as crianças institucionalizadas. Consequentemente, a falta de preparo das cuidadoras, muitas vezes priva as crianças da possibilidade de brincar e explorar o ambiente, além de dificultar o diálogo e o lidar com crianças que apresentem necessidades especiais (ANDRADE, FIAMENGHIJR, 2018).

De fato, como mostram Barros e Naiff (2015), existe uma expectativa de que a capacitação possa funcionar como um espaço de troca profissional e como suporte para instrumentalizá-los nas intervenções cotidianas.

Compreende-se o papel significativo das cuidadoras no processo de abrigamento, no que se refere ao acolhimento, possibilitando o desenvolvimento com menos prejuízo psíquico, uma vez que as cuidadoras apresentem funções de amparo, continência, segurança, carinho e afetividade e deste modo contribuem para que estas crianças estabeleçam relações vinculares eficientes, desenvolvendo-se de forma saudável e proporcionando a constituição de outras relações vinculares no decorrer de suas vidas. 
Além disso, como demonstra o trabalho de Guedes e Scarcelli (2014) no cotidiano do processo de institucionalização, as práticas sociais atribuem papeis a cada um dos envolvidos no universo do cuidado.

Portanto, o presente estudo buscou compreender a importância do cuidado e acolhimento realizado por parte das cuidadoras, na construção do vínculo, visando a redução do sofrimento de crianças institucionalizadas.

\section{MATERIAIS E MÉTODOS}

A pesquisa foi realizada em uma Associação que abriga cerca de cinquenta crianças de ambos os sexos, de zero até os 18 anos. Esta associação sobrevive a partir de doações, mensalidades e verbas do poder público e localiza-se no interior do estado de São Paulo e tem seu trabalho baseado no Estatuto da Criança e do Adolescente (ECA), que garante os direitos dos abrigados. O cuidado é realizado vinte $\mathrm{e}$ quatro horas por dia, com cuidadoras no período diurno e noturno.

\section{Participantes}

Apesar de a instituição acolher crianças e adolescentes até os 18 anos, apenas nove cuidadoras efetivas da instituição, com idades entre 20 e 50 anos, que atuam com crianças entre 0 e 4 anos e 11 meses, aceitaram participar da pesquisa voluntariamente $\mathrm{O}$ estudo foi autorizado pelo Comitê de Ética em Pesquisa, protocolo 13-05/227.

\section{Instrumentos}

O instrumento para a coleta de dados foi uma entrevista semiestruturada desenvolvida pelos pesquisadores contendo questões abertas, versando sobre: função desempenhada, idade, estado civil, tipo de cuidado desempenhado com as crianças, o estabelecimento e a relação de vínculos, entre outras questões que poderiam afetar no desenvolvimento psíquico das crianças institucionalizadas.

\section{Procedimentos de coleta e análise dos dados}

Após os esclarecimentos necessários e assinatura do Termo de Consentimento Livre e Esclarecido, foi realizada uma entrevista semiestruturada individualmente, em uma sala reservada nas dependências da instituição, que permitiu o maior esclarecimento sobre a rotina e percepções das cuidadoras. Cada entrevista durou aproximadamente, uma hora. As entrevistas foram gravadas e transcritas literalmente, para a análise dos resultados.

\section{RESULTADOS E DISCUSSÃO}

A questão 1 referia-se às principais necessidades apresentadas pelas crianças atendidas na instituição, e as respostas apresentadas relacionavamse ao fornecimento de atenção, carinho, amor, presença e cuidado dos pais, seja eles biológicos ou adotivos, além de relatos da importância do respeito à história de vida das crianças, e em promover a individualidade e exclusividade, pois todos os objetos do abrigo são usados coletivamente, como relata a Cuidadora 2: "Precisam de amor, são carentes, precisam de atenção e carinho. Eles têm tudo, alimento, roupas, brinquedos, mas não têm a mãe e o pai, que é o mais necessário, e então me apego muito a elas".

Do ponto de vista da estruturação psíquica, o processo de cuidado deve promover um sentimento de um indivíduo inteiro, de forma a facilitar o desenvolvimento gradual do ego (SPITZ, 1965), e de forma a auxiliar no desenvolvimento da saúde mental da criança (BOWLBY, 1976). Também como apontado por Winnicott (1965), o cuidado fornecido pelas cuidadoras pode servir de substituto da função 
materna no que se refere à possibilidade de desenvolvimento e identificação (MARQUES, CANO, VENDRUSCOLO, 2007; TAGLIARI, 2011).

Referente à questão 2, sobre os sentimentos apresentados no cuidado diário com as crianças, as cuidadoras comparavam as crianças com seus filhos. Descreveram sentimentos de carinho, amor, apego, saudade ao fim do expediente, alegria em poder ajudá-los e o quanto se doam para essa função. Também apresentaram sentimentos de gratificação, afeto, proteção e o sentimento de dó pela falta da família na vivência das crianças, como a Cuidadora 1 : "Amo eles [chora], porque eles me chamam de mãe, sinto dó e penso nos meus filhos, penso no futuro destas crianças, como vai ser?". Também, a Cuidadora 6 disse: "Sinto que deixo alguém quando vou embora. Me apego muito e me apego como mãe e sinto saudade. Sinto dó pela vivencia deles, mas me alegro, pois eles entram na instituição para melhorar a vida. Eles são vítimas".

A partir das respostas das cuidadoras é possível refletir sobre a necessidade de alguém que se responsabilize pelo cuidado da criança, num relacionamento estável, possibilitando um desenvolvimento saudável (BOWLBY, 1976; WINNICOTT, 1988).

$\mathrm{Na}$ questão 3, as cuidadoras expuseram a falta de funcionários como fator de maior problema, devido à alta rotatividade, gerando a dificuldade de fornecer atenção e o cuidado necessário, pois são muitas crianças. Relataram o despreparo delas diante dos conflitos entre as crianças e os questionamentos; a falta de padronização da rotina diária de trabalho e de função específica (cuidado de crianças maiores e menores); falta de atividades diferenciadas para as crianças; e dificuldades diante da infraestrutura do ambiente, onde as crianças passam a maior parte do tempo. A Cuidadora 6 comenta que: "Uma das dificuldades é que as crianças estão juntas (bebês e os maiores), precisam de organização no cuidado. Acho que as monitoras precisam passar por palestras para serem orientadas quanto ao lidar com as crianças e saber entender as suas crianças. Precisamos de mais monitoras para ajudar". A Cuidadora 8 continua: "O espaço é pequeno e fica longe o banheiro, a infraestrutura, o lugar para tomarem sol. Sinto falta de uma oficina terapêutica para as crianças, sinto falta de atividades para elas". E, a Cuidadora 4 explica que: "Aqui o cuidado é de higiene, alimentação e físico. Faltam funcionários e a rotatividade é muito grande".

Diante dos relatos das cuidadoras que expuseram as dificuldades encontradas, tais crianças deveriam ter o direito de receber o acolhimento essencial, atendimento personalizado ou em pequenos grupos, além da reinserção na comunidade com a realização de atividades (BRASIL, 1990; SOUZA, BRITO, 2015). Um dos principais problemas citados pelos pesquisadores é a falta de preparo das cuidadoras, no que se refere às fases de desenvolvimento das crianças e nas maneiras adequadas de lidar com elas (BARROS, FIAMENGHI-JR，2007; MARQUES， CANO, VENDRUCOLO, 2007; BARROS, NAIFF, 2015; ANDRADE, FIAMENGHI-JR, 2018). Cavalcante, Magalhães e Pontes (2007) explicam que o ambiente institucional pode expor a criança a um cuidado impessoal e pouco estável, sendo este um fator de risco à saúde física, emocional e psíquica.

A questão 4 analisa o estabelecimento do vínculo das cuidadoras com as crianças e a resposta mais evidente refere-se, a proporcionar educação, estabelecer limites, repreensão de comportamentos que julgam inadequados. Também expuseram como forma de estabelecimento de vínculo, o momento da alimentação; a dedicação de tempo em dar carinho, no diálogo e na relação que sentem de mãe e filho e no estabelecer confiança e respeito, conforme a fala 
da Cuidadora 8: "O vínculo é estabelecido no dia a dia, no conhecimento das coisas que vão acontecendo com o tempo, mas sempre existe uma preferência e sinto que elas escolhem. $O$ vínculo se dá no banho, no pegar, você está cuidando, educando e no almoço vai conhecendo ela, e ela conhece você". A Cuidadora 3 também explica: "Com cada monitora é diferente, mas comigo é dando respeito, com tempo para dar carinho, tempo para educar, dar amor, me sinto mãe, mãe impõe limites".

Spitz (1965), afirma que a criança em seu desenvolvimento necessita adquirir limites e experimentar suas capacidades, mas somente quando há troca de relações afetivas, podendo ser representadas inicialmente pela mãe e, posteriormente, com amigos e familiares, auxiliando na estruturação do ego. No contexto da instituição, as cuidadoras representam estas figuras significativas na formação da instância psíquica (TAGLIARI, 2011).

$\mathrm{Na}$ questão 5, abordando o que as motivava em trabalhar em uma instituição de abrigo, destacouse o fato de gostarem de crianças, além de sentirem que as crianças são dependentes do cuidado fornecido por elas e que este ato pode transformar suas vidas, como define a Cuidadora 7: "Me superei como pessoa, sou muito sensível e sinto que posso transformar a vida dessas crianças fazendo a diferença na vida deles. Quero ser mãe, pois sempre gostei de crianças".

A função representada pelo cuidado da mãe estabelece a estruturação do ego da criança, daí a importância de vínculos estáveis nessas condições de institucionalização BOWLBY, 1976; (WINNICOTT, 1965). As crianças precisam de ambiente que proporcione acolhimento, segurança e proteção (SANTOS e cols., 2010).

A questão 6 referia-se às mudanças na vida pessoal das cuidadoras, em decorrência do trabalho institucional. Todas as cuidadoras afirmaram que o trabalho permite reflexões sobre a sua vida e seu valor e o quanto aprenderam a perceber o outro, inclusive a família. Afirmam terem aprendido a se relacionar melhor, serem mais responsáveis e pacientes. Podemos exemplificar com o relato da Cuidadora 9: "Sim, acredito em mim mesma, me sinto mais confiante. Sei que dei muito trabalho ao meu pai. Refleti na vida e dou mais valor à família. Me coloco no lugar das crianças (chorou)", bem como o da Cuidadora 8: "Aprendo a cada dia com eles, aprendi a encarar a vida de outra forma, tudo era visto com dificuldade e agora me sinto abençoada por Deus. Aprendi que não tenho dificuldade, difícil é o que as crianças vivem aqui”.

$\mathrm{O}$ ato de cuidar e sentir-se responsáveis pelas crianças atribui-se ao sentimento materno (BOWLBY, 1976; WINNICOTT, 1965). Para que a criança desenvolva sentimentos saudáveis, é necessário que tenha presente uma figura humana, não rígida, mas viva que possa lhe fazer sentir-se segura (WINNICOTT, 1965).

Quanto à pergunta 7, sobre o entendimento delas como figura materna no cuidado com as crianças, as cuidadoras disseram que se sentem responsáveis por elas, seja no cuidado, na repreensão, na alimentação ou higienização, onde demonstra respeito, afeição, carinho através de gestos e no olhar. Afirmam reconhecer que substituem o papel da mãe, como diz a Cuidadora 5: "Sim, porque quando chega algum recém-nascido me preocupo com sua hora de alimentação e na quantidade de alimento. Sinto que eles já me veem como mãe, pois passo segurança”. A Cuidadora 6 ainda afirma que: "Sim, pai e mãe somos nós, que temos a função de cuidar, ensinar e educar".

Segundo Marques, Cano e Vendruscolo (2007), as cuidadoras colocam-se como fornecedoras de cuidados físico e mental e compreendem que os cuidados necessários vão além dos cuidados básicos e devem abranger o fornecimento moral e emocional. 
Porém, necessitam formação adequada, para que estes cuidados sejam fornecidos de forma mais efetiva (BARROS, FIAMENGHI-JR, 2007; BARROS, NAIFF, 2015).

Na questão 8, ao serem questionadas sobre a importância do vínculo no processo de abrigamento, uma das cuidadoras apresentou dúvidas se poderia demonstrar amor pelas crianças, pois receberam orientações para não se apegarem durante o tempo no abrigo. Porém todas elas afirmaram que reconhecem a importância do vínculo, mas que sofrem quando são adotadas, ou retornam aos seus lares. Compreendem que desta forma podem suprir a falta dos pais e o convívio do lar (GUEDES, SCARCELLI, 2014). Por exemplo, o relato da Cuidadora 1: "Sim, pois precisam desse vínculo. Fico triste quando eles vão embora, mas também feliz em saber foram adotados, prefiro que sejam adotados do que voltarem para suas famílias, porque acredito que vão sofrer de novo as mesmas coisas". E o da Cuidadora 3: "Sim, porque já vieram de situações difíceis e eles precisam sentir confiança e proporciono a confiança, procurando brincar, acariciar e demonstrar no olhar o carinho. Nos momentos vagos, tento dar o máximo de atenção".

Segundo Careta (2011), o estabelecimento do vínculo consiste na responsabilidade de cuidado na rotina diária, em que se refere à higiene, alimentação, cuidados físicos, além da participação em programas culturais, escolares e cuidado com a saúde. Tagliari (2011) citou como forma de vinculação, a preocupação das cuidadoras com o futuro em poder contribuir em seu desenvolvimento social saudável e mais digno.

Finalmente, a questão 9, ao investigar como as cuidadoras expressam o afeto, teve como relatos abraços, beijos, conversas, respeito, dar amor, carinho e inclusive, impor limites. Citaram que todos estes cuidados são dados nos momentos em que há tempo disponível, ou no banho, um momento único e individualizado. Informaram que a alimentação também possibilita uma forma de demonstrar este afeto, pois isto é uma preocupação materna e são orientadas, ao alimentarem os bebês, da importância do olhar nos olhos das crianças. Também, na hora de dormir, quando tentam deitar junto com as crianças, percebendo que estes momentos permitem esboçar a afetividade, como explica a Cuidadora 2: " $E m$ primeiro lugar, é o respeito, amar e dar carinho, e tem horas que tem que ser mais dura, porque se não, perdemos o controle, e ai tem que conversar $e$ explicar. Somos orientadas a pegar no colo, mas não a todo tempo, pegamos mais os pequenos".

Ao compreender o trabalho realizado pelas cuidadoras, o ECA (BRASIL, 1990), assegura o cuidado integral no âmbito físico e social. Winnicott (1965) destaca o toque como contato com a realidade externa, proporcionando sentimentos de segurança, proteção e ressalta a importância de as crianças sentirem-se seguras para o estabelecimento de confiança no ambiente, pois caso contrário poderá apresentar distorções em seu desenvolvimento. Finalmente, a afetividade vivenciada por estas crianças, possibilita a constituição de outras relações vinculares (OLIVEIRA, PRÓCHNO, 2010).

\section{CONCLUSÃO}

As cuidadoras entrevistadas apresentam um bom vínculo com as crianças, pois se percebem como figuras maternas significativas na vida delas. Quanto ao estabelecimento de vínculo e demonstração de afetividade, observou-se que suas respostas correspondem às necessidades das crianças, de higienização, alimentação, calor humano, respeito e principalmente, a educação, no estabelecimento de limites. Compreende-se que esse cuidado pode possibilitar a amenização dos prejuízos causados pela 
institucionalização, devido ao rompimento do vínculo materno.

Em contrapartida, as cuidadoras demonstraram um descontentamento com a instituição, quanto ao número reduzido de funcionárias, destacando a alta rotatividade como um fator que prejudica o acolhimento das crianças no cuidado, o que faz a demonstração de afetividade ser disponível somente em períodos restritos.

Um ponto relevante que as cuidadoras apresentaram corresponde à dificuldade em compreender o limite de envolvimento afetivo entre elas e as crianças, para que seja uma relação saudável para ambas.

Levanta-se também a hipótese de que esta vinculação possa aflorar as questões maternas e de filiação, e então também trazer dificuldades emocionais, visto que relataram sentimentos de abandono, ou algum tipo de negligência, quando vão embora para suas casas.

De forma geral, conseguiu-se verificar a importância de as cuidadoras compreenderem a importância dos cuidados em todas as circunstâncias, para o desenvolvimento saudável. Além disso, a função materna exercida pelas cuidadoras pode propiciar às crianças institucionalizadas segurança confiança e autonomia, permitindo o crescimento e fortalecimento emocional duradouro.

Estudos futuros necessitariam focar em cuidadoras que lidam com crianças maiores, pois este ficou limitado pela faixa etária das crianças envolvidas.

Todos os autores declararam não haver qualquer potencial conflito de interesses referente a este artigo.

\section{REFERÊNCIAS}

ANDRADE, A.F; FIAMENGHI-JR, G.A. Sheltered children's psychological suffering and carers' lack of training: observations from a Brazilian sheltered DOI: http://dx.doi.org/10.20873/uftv7-5225 home. International Journal of Social Sciences Perspectives, v. 3, n. 1, p. 34-37, 2018.

BARROS, R.C.; FIAMENGHI-JR, G.A. Interações afetivas de crianças abrigadas: um estudo etnográfico. Ciência \& Saúde Coletiva, v. 12, n. 5, p. 1267-1276, 2007.

BARROS, N.S.; NAIFF, L.A.M. Capacitação para educadores de abrigo de crianças e adolescentes: identificando representações sociais. Estudos e Pesquisas em Psicologia (Rio de Janeiro), v. 15, n. 1, p. 240-259, 2015.

BOWLBY J. Cuidados maternos e saúde mental. São Paulo: Editora Martins Fontes, 1976.

BRASIL. Estatuto da criança e do adolescente (ECA). Lei $\mathrm{n}^{\mathrm{o}}$ 8.069, de 13 de julho de 1990. Brasília, DF, 1990.

CARETA, D.S. Quando o ambiente é o abrigo: cuidando das cuidadoras de crianças em acolhimento institucional. Tese de Doutorado. Instituto de Psicologia da Universidade de São Paulo. São Paulo, 2011.

CAVALCANTE， L.I.; MAGALHÃES， C.M.C.; PONTES, F.A.R. Institucionalização precoce $\mathrm{e}$ prolongada de crianças: discutindo aspectos decisivos para o desenvolvimento. Aletheia, v. 25, p. 20-34, 2007.

GUEDES, C.F.; SCARCELLI, I.R. Acolhimento institucional na assistência à infância: o cotidiano em questão. Psicologia \& Sociedade; v 26 (n. spe.), p.58-67, 2014.

MARQUES, C.M.L.; CANO, M.A.T.; VENDRUSCOLO, T.S. A percepção dos cuidadores sociais de crianças em abrigos em relação ao processo do cuidar. Revista Serviço Social \& Realidade, v. 16, n. 2, 22-41, 2007.

OLIVEIRA, S.V.; PRÓCHNO, C.C.S.C. A vinculação afetiva para crianças institucionalizadas à espera de adoção. Revista Psicologia: Ciência e Profissão, v. 30, n. 1, 2010.

Revista Desafios - v. 7, n. 1, 2020 
SANTOS, B.C.A.; RIBEIRO M.C.C.; UKITA, G.M.; PEREIRA, M.P.; DUARTE, W.F.; CUSTÓDIO, E. M. Características emocionais e traços de personalidade em crianças institucionalizadas e não institucionalizadas. Boletim de Psicologia, LX (133), p. 139-152, 2010.

SOUZA, F.H.O; BRITO, L.M.T. Acolhimento institucional de crianças e adolescentes em Aracaju. Psicologia Clínica (Rio de Janeiro), vol. 27, n.1, p. 41-57, 2015.
SPITZ, A.H. O primeiro ano de vida. São Paulo: Editora Martins Fontes, 1965.

TAGLIARI, E. Dificuldades do vínculo familiar e social em crianças adotivas. Trabalho de Conclusão de Curso, Faculdades Integradas Einstein de Limeira (FIEL), Limeira, 2011.

WINNICOTT, D.W. A família e o desenvolvimento individual. São Paulo: Editora Martins Fontes, 1965. WINNICOTT, D.W. Natureza humana. Rio de Janeiro: Editora Imago, 1988. 